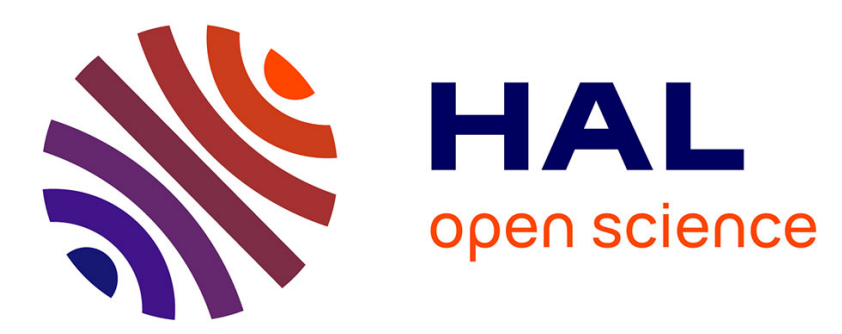

\title{
Local Study of Thin-Film Adhesion by Surface Acoustic Waves and Subsurface Acoustic Microscopy Imaging
}

\author{
Patrick Richard, G. Gremaud, J. Thomas, A. Kulik, W. Benoit
}

\section{To cite this version:}

Patrick Richard, G. Gremaud, J. Thomas, A. Kulik, W. Benoit. Local Study of Thin-Film Adhesion by Surface Acoustic Waves and Subsurface Acoustic Microscopy Imaging. Journal de Physique IV Proceedings, 1996, 06 (C8), pp.C8-795-C8-798. 10.1051/jp4:19968170 . jpa-00254606

\section{HAL Id: jpa-00254606 https://hal.science/jpa-00254606}

Submitted on 1 Jan 1996

HAL is a multi-disciplinary open access archive for the deposit and dissemination of scientific research documents, whether they are published or not. The documents may come from teaching and research institutions in France or abroad, or from public or private research centers.
L'archive ouverte pluridisciplinaire HAL, est destinée au dépôt et à la diffusion de documents scientifiques de niveau recherche, publiés ou non, émanant des établissements d'enseignement et de recherche français ou étrangers, des laboratoires publics ou privés. 


\title{
Local Study of Thin-Film Adhesion by Surface Acoustic Waves and Subsurface Acoustic Microscopy Imaging
}

\author{
P. Richard, G. Gremaud, J. Thomas*, A. Kulik and W. Benoit \\ Ecole Polytechnique Fédérale de Lausanne, Département de Physique, Institut de Génie Atomique, \\ 1015 Lausanne, Switzerland \\ * Ecole Polytechnique Fédérale de Lausanne, Département des Matériaux, Laboratoire de Métallurgie \\ Chimique, 1015 Lausanne, Switzerland
}

\begin{abstract}
Four thin-film adhesion characterization methods are proposed. Two of them are surface acoustic wave based and the two others emphasize the complementary nature between acoustic microscopy, scratch test and tensile experiments. A continuous wave scanning acoustic microscope was used to propagate surface modes in the specimen and to measure the surface acoustic wave velocity as a function of the frequency. Characteristic equations have been calculated for generalized Lamb wave and generalized surface skimming compressional wave modes as a function of interface boundary conditions and frequency. Experimental surface acoustic wave velocity dispersion curves and numerically evaluated ones have been compared in shape and absolute position. It has been shown that this comparison allows one to characterize the interface preparation quality or adhesion property of thin films deposited by Physical Vapour Deposition (PVD). Two original coupling techniques were developed to increase the comprehension of intermediate adhesion states and thin-film delamination initiation and propagation characteristics. The first applies tensile stress to thin-film specimens directly under the microscope and the other creates a typical scratch at the top of the layered sample before surface and interface acoustic microscopy observations.
\end{abstract}

\section{INTRODUCTION}

The Scanning Acoustic Microscope (SAM) first introduced by Lemons and Quate in 1974 [1] is able to excite and measure Surface Acoustic Waves (SAW) at the surface of bulk or layered samples. It is now established that the experimental SAW dispersion curves are perfectly reproduced by the theoretical models for highly adherent films when the elastic parameters of the system are known. Under these conditions it should be possible to study film adhesion by measuring their influence on the SAW velocity [2]. That is what has been done experimentally with the Continuous Wave-SAM (CW-SAM) and theoretically with the development of interface models for comparison with the experimental data.

Interface acoustic imaging is well known for its adhesion defect contrast. The original aspect of the second part of this work is to use it with complementary techniques to introduce stresses at the filmsubstrate interface for quantitative adhesion characterization and dynamic observation of adhesion defect initiation and propagation.

\section{THEORY}

The SAW propagation characteristics in perfectly adherent thin films deposited on semi-infinite substrates are determined by the dispersion relation of Generalized Lamb Waves (GLW) [3]. These waves have mainly a transverse polarization and are close to the Rayleigh wave velocity of the substrate at low frequency. The longitudinal polarized Generalized Surface Skimming Compressional Waves (GSSCW) could also be excited in thin film deposited on some substrate materials with the CW-SAM. The dispersion curves of such modes could be calculated with the help of a complex reflection coefficient [4]. Their velocity at low frequency is close to the longitudinal wave velocity of the substrate.

Interface models for both of these types of SAW were theoretically developed and the corresponding dispersion curves calculated [5]. In each case, an adhesion decrease leads to a lower surface acoustic wave velocity. 


\section{EXPERIMENTAL PROCEDURES}

The SAW velocity measurements were performed in the metrology mode of the CW-SAM described elsewhere [6]. The SAW velocity is obtained through the FFT analysis of the CW-V(z) acoustic material signature [7]. A homemade high precision tensile micro-machine compatible with the acoustic microscopes was used to apply interfacial stresses to layered specimens [5]. The scratch test installation described by Frey et al. [8] was used to introduce delamination of coating before observations with the Leitz-ELSAM imaging acoustic microscope [9].

\section{RESULTS AND DISCUSSION}

\subsection{Generalized Lamb wave and adhesion}

The absolute comparison of the position and shape of the experimental and calculated GLW dispersion curves allows one a precise determination of perfectly adherent and totally delaminated films. The results for a perfectly adherent nickel film electrodeposited on aluminum and a free aluminum film were given elsewhere [10]. The intermediate adhesion states were not emphasized with GLW.

\subsection{Generalized surface skimming compressional waves and adhesion}

The same type of comparison is presented in Fig. 1 for the GSSCWs dispersion curves. The experimental data are the black dots. The top curve (---) is calculated for a perfect interface, the middle curve ( $\cdots)$ for a "nearly-weak" interface [5] and the bottom curve (---) for a nearly free film. Figure 1a) shows the results for a $0.769 \mu \mathrm{m}$ thick copper film deposited by $P V D$ on glass. Figure $1 \mathrm{~b}$ ) displays the results for the same specimen after a thermal treatment (isochronal annealing at $200^{\circ} \mathrm{C}$ and $400^{\circ} \mathrm{C}$ ). The latter induces interface adhesion defects and also a small reduction of the film thickness.
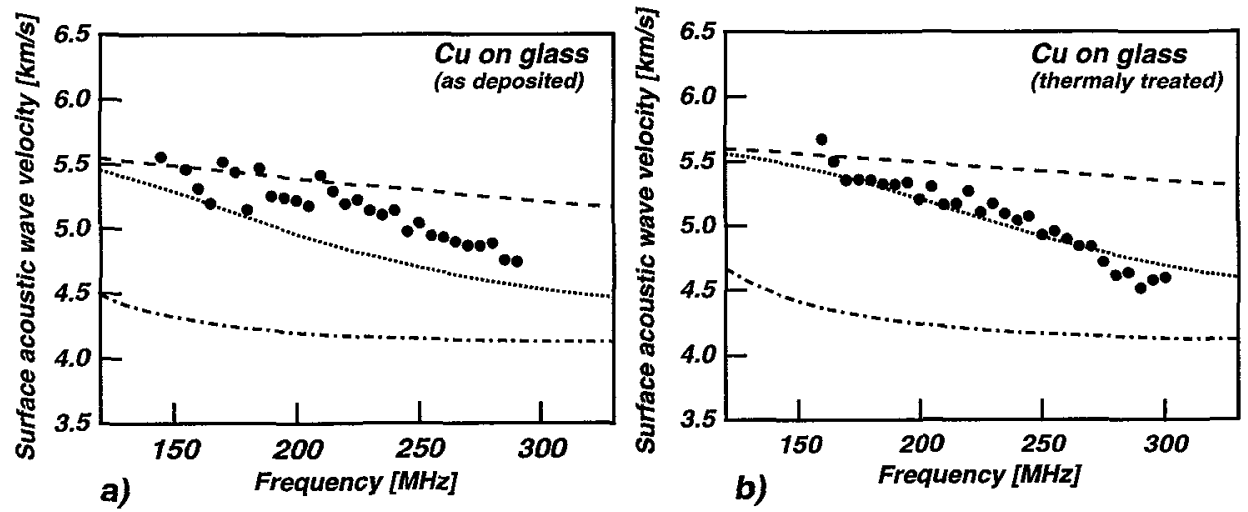

Figure 1: Dispersion curves of GSSCW as a function of adhesion a) for a copper film $0.769 \mu \mathrm{m}$ thick deposited by $P V D$ on glass, b) for the same film after a thermal treatment (isochronal annealing at $200^{\circ} \mathrm{C}$ and $400^{\circ} \mathrm{C}$ ). The continuous curves are the dispersion relations calculated for perfect interface, "nearly-weak" interface and nearly free film (in order from the top to the bottom).

The observed decrease of the GSSCW velocity after the thermal treatment has been attributed to the decrease of adhesion. This type of SAWs seems to be more sensitive to intermediate adhesion states than the GLW ones.

\subsection{Coupled method I: adhesion characterization by traction and acoustic microscopy}

The first coupled method that was proposed to characterize adhesion is to measure the variation of GLW velocity as a function of an in-situ applied traction stress to the specimen. Figure 2 is obtained by successive SAW velocity measurements at $200 \mathrm{MHz}$ during the increase of the applied traction force. The first part of the experimental curve is located at the generalized Lamb wave velocity calculated at $200 \mathrm{MHz}$ for a perfect interface indicated by the lower dashed line. After the adhesion failure of the nickel film arising at $140.8 \mathrm{~N}$ which corresponds to an interfacial shear stress of $89.81 \mathrm{MPa}$, the second part of the experimental curve tends towards the Rayleigh wave velocity of the substrate material indicated by the upper dashed line. This observed SAW velocity discontinuity is the consequence of the coating 
delamination under the acoustic lens. The coating buckling (originating from the contraction of the sample by the Poisson modulus effect) and the water (coupling fluid) intrusion at the interface explain the ultrasound propagation through the coating and the Rayleigh wave excitation at the top of the substrate.

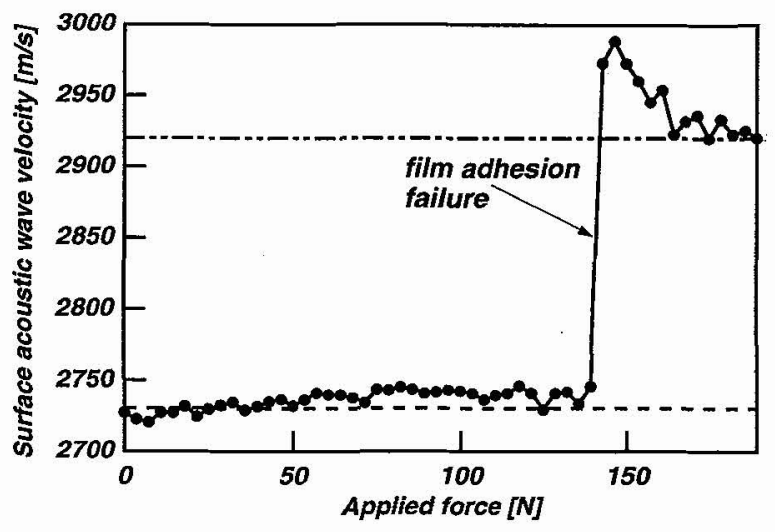

Figure 2: Adhesion failure of a $0.54 \mu \mathrm{m}$ thick nickel film deposited by $P V D$ on an aluminum substrate. The GLW velocity is measured by the CW-SAM at $200 \mathrm{MHz}$ as a function of the applied force on the dog-bone shaped sample. The nickel film is deposited only in the middle of the sample and a very thin intermediate carbon film was used to modify the interfacial shear stress. The film failure appears at the applied force of $140.8 \mathrm{~N}$ which corresponds to an interfacial shear stress of $89.81 \mathrm{MPa}$. Before this point the SAW velocity is at the level of the corresponding velocity at this frequency of the generalized Lamb waves and after the failure the SAW velocity is at the Rayleigh wave velocity in the substrate.

Different SAW velocity behavior could be observed for film buckling at a smaller size in regard to the spot diameter on the sample where the SAW propagates (under the acoustic lens). If the film is partly adherent and partly delaminated at this scale, the acoustic wave velocity could tend towards the calculated value of the generalized Lamb wave calculated for a weak interface at $200 \mathrm{MHz}$.

Acoustic microscopy observations have been performed with the Leitz-ELSAM microscope on the same kind of sample to observe the effect of water intrusion presented above to interpret the Fig. 2 and to observe the dynamic evolution of the delamination propagation for the specimen under traction stress. Figure 3a) shows the adhesion defects spontaneously created by water intrusion after an immersion time of 2 minutes. This delaminated configuration is stable even for a longer immersion time. The weak applied force in this case is only aimed to maintain the layered sample at focus. The applied force is then increased successively to initiate traction stress induced delamination. Figure $3 \mathrm{~b}$ ) illustrates the initiation of arrow shaped adhesion defects. The defects propagate in the direction of the horizontal lamination grooves (which is also the direction of the applied stress) for increasing forces. This dynamic evolution of the delaminated surface is illustrated Figs. 3c) and d). The observed interference fringes on these acoustic images are coming from the contrast due to the upraising of the delaminated zones. Knowing that the vertical distance between two fringes is one half of the wavelength, their configuration in contour-line structure gives a precise idea of the coating uprising geometry.
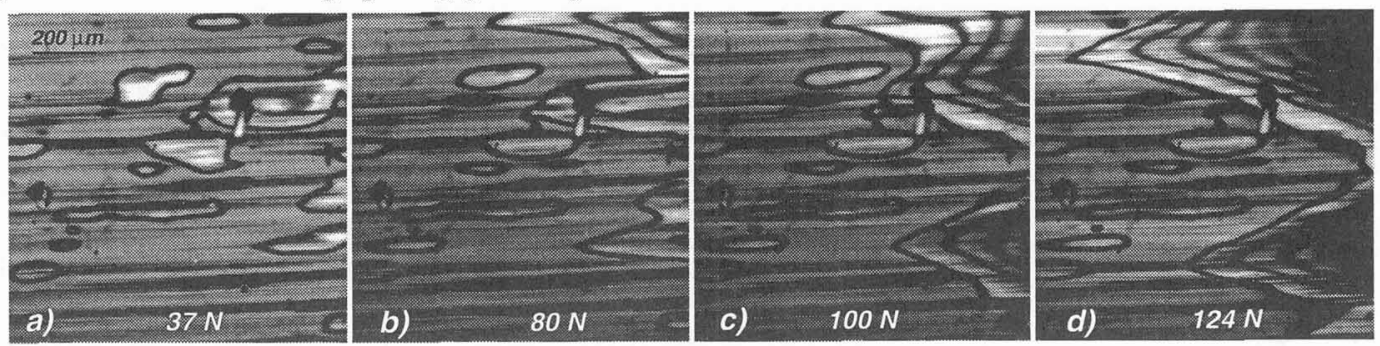

Figure 3: Acoustic images of an adhesion failure due to the intrusion of the coupling fluid at the interface and to the effect of an applied stress. The sample is similar to the one of Fig. 2. a) Adhesion defects spontaneously created, b), c) and d) Arrow-shaped adhesion defects induced by the external applied traction stress, they propagate in the direction of the horizontal lamination grooves which is also the direction of the applied stress.

\subsection{Coupled method II: adhesion characterization by scratch test and acoustic microscopy}

Adhesion defects have been introduced in a composite nickel film, $25 \mu \mathrm{m}$ thick reinforced with silicon carbide particles, by the movement of the diamond indenter of a classical scratch test experiment. Such samples were then observed by acoustic microscopy. Figure 4 a) is an acoustic surface image (close to an optical one) which shows the scratch groove, a removed part of the coating and the bright, uniform and flat coating surface. Figure $4 \mathrm{~b}$ ) has been obtained thanks to the ability of ultrasound to penetrate opaque 
materials. This is an interface image (with the focal plane at the coating-surface interface) [11]. It shows an astonishing adhesion defect contrast (in bright) all around the scratch which is due to the delamination induced by the scratch experiment. No other visualization technique is able to detect such features as a function of depth. Finally, the recorded normal and tangential forces curves during the scratch and the delaminated surfaces detected by acoustic microscopy could be used to determine the coating adhesion energy.

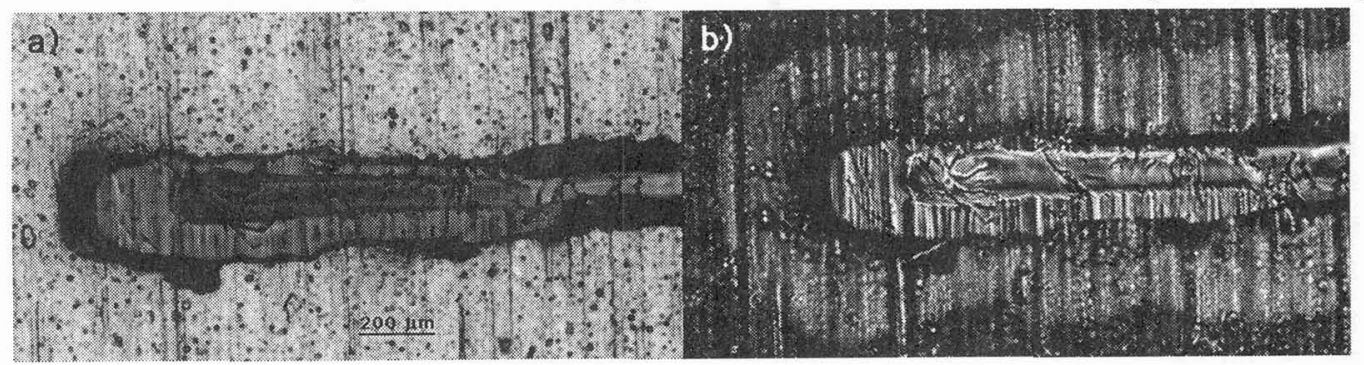

Figure 4: Acoustic images at $217 \mathrm{MHz}$ of the same end of a scratch made on a composite nickel film $25 \mu \mathrm{m}$ thick reinforced with silicon carbide particles. The film is electrodeposited on gray cast iron. The substrate was not well cleaned in order to produce intermediate adhesion. a) Surface (focalization at $z=0$ )) image with a very uniform topography contrast around the scratch, b) interface focalization $(z=-74 \mu \mathrm{m})$ with a high adhesion defect contrast around the scratch. The scratch groove is visible in the center of both images as well as a removed part of the coating.

\section{CONCLUSION}

The complementary nature of the generalized Lamb waves and the surface skimming compressional waves, from the adhesion characterization point of view, was used to study a wide range of film adhesion values. To our knowledge the adhesion effect on the GSSCW dispersion curves was neither observed nor calculated before. The major limitation of the surface acoustic wave technique is the degree of confidence of the system mechanical parameters which are used as input values for the dispersion curve calculations.

The coupling between acoustic microscopy and tensile experiments provides useful information on the type of adhesion failure, the interfacial shear stress, the interfacial structure and the dynamic evolution of delaminated areas.

Finally, the combination of scratch test and acoustic microscopy constitutes a more quantitative adhesion characterization method which no longer needs a hypothetical adhesion criterion to be defined. Using the scratch force curves and the delaminated area on the acoustic image this technique could give the coating adhesion energy.

\section{Acknowledgments}

The Priority Program on Materials Research of the Board of the Swiss Federal Institutes of Technology BSIT has partially supported this work.

\section{References}

1. R. A. Lemons, C. F. Quate, Appl. Phys. Lett. 24, 163-165 (1974).

2. L. Adler, M. d. Billy, G. Quentin, M. Talmant, P. B. Nagy, J. Appl. Phys. 68, 6072-6076 (1990).

3. G. W. Farnell, E. L. Adler, in Physical Acoustics W. P. Mason, R. N. Thurston, Eds. (Academic Press, New York, 1972), vol. 9, pp. 35-127.

4. A. Briggs, Acoustic Microscopy. R. Brook, P. B. Hirsch, C. J. Humphreys, N. F. Mott, Eds., Monographs on the Physics and Chemistry of Materials (Oxford University Press, Oxford, 1992), vol. 47, pp. 201-231.

5. P. Richard, Thèse, EPFL, Lausanne, Switzerland (1996).

6. A. Kulik, G. Gremaud, S. Sathish, Continuous Wave Reflection Scanning Acoustic Microscope, H. Schimizu, N. Chubachi, J. Kushibiki, Eds., Acoustical Imaging 17, (Plenum Press, New-York, 1989) 71-78.

7. A. Kulik, G. Gremaud, S. Sathish, Direct Measurement of the SAW Velocity and Attenuation Using Continuous Wave Reflection Scanning Acoustic Microscope, H. Lee, G. Wade, Eds., Acoustical Imaging 18, Santa Barbara, USA, (Plenum Press, New York, 1989) 227-235.

8. N. Frey, P. Mettraux, G. Zambelli, D. Landolt, Surf. Coat. Technol. 63, 167-172 (1994).

9. V. A. Thaer, M. Hoppe, W. J. Patzelt, LEITZ-Mitt. u. Techn. VIII, 61-67 (1982).

10. P. Richard, G. Gremaud, A. Kulik, Thin Film Adhesion Investigation with the Acoustic Microscope, M. Levy, S. C. Schneider, B. R. McAvoy, Eds., IEEE Ultrasonics International Symposium, Cannes, France (1994) 1425-1428.

11. J. Thomas, P. Richard, D. Landolt, G. Gremaud, Submitted to Surf. Coat. Techn. (1996). 